\title{
Fibrous dysplasia of right hip bone-rare disease: A case report
}

\author{
Hina Aslam ${ }^{1}$, Nazia Yousef ${ }^{2 *}$ and Sana Sehar ${ }^{1}$ \\ 1. Department of Nursing, The University of Lahore, Lahore-Pakistan \\ 2. Department of Nursing, The Superior University Lahore-Pakistan \\ *Corresponding author's email: naziayousif19@ gmail.com \\ Citation \\ Hina Aslam, Nazia Yousef and Sana Sehar. Fibrous dysplasia of right hip bone-rare disease: A case report. Pure and \\ Applied Biology. Vol. 9, Issue 3, pp1718-1722. http://dx.doi.org/10.19045/bspab.2020.90182 \\ \begin{tabular}{llll}
\hline \hline Received: 01/01/2020 & Revised: 22/03/2020 & Accepted: 03/04/2020 & Online First: 08/04/2020 \\
\hline
\end{tabular}
}

\section{Abstract}

Fibrous dysplasia is a rare disease of bones in which osteoblasts cells abnormally differentiate leading to woven immature bone formation by replacement of normal canellous bone cells. This is considered to be originated by misssense gene mutation at chromosome 20q13.FD may involve one bone (monostotic) or more than one bone (polystotic). It can involve any bone in human body but the long bone, skull, and ribs are common. A 24 years old female visited hospital with a complaint of right hip pain and backache for last 07 months. Pain was dull in nature, increased both in frequency and intensity with the course of time, radiating to right leg, aggravated by movements. Patient had a previous history of 03 months aggressive gym exercises till February 2019, when she developed this pain. Patient also manifested the history of polycystic ovarian syndrome. There was no other history of systemic illness. On X-ray of Pelvis (AP-view) there was bubbly appearance of right iliac bone with thickening of the trabeculi in proximal end of both femora. On MRI Abnormal bone marrow signals were noted in right iliac bone. Loss of cortical margins is seen both anteriorly and posteriorly White zone of transition is noted. Inferiorly it extends to the superior and anterior acetabular margins. Histopathologically the blood and scattered inflammatory cells were present. There was strong suspicion of fibrous dysplasia. No neoplastic cells were found. In surgical treatment, excision of the lesion and bone grafting was done. Pharmacological interventions were analgesics, bisphosphonates, oral calcium supplements, and Proton pump inhibitors. Patient reported 70-80\% in relief of symptoms after surgery. Patient was discharged from hospital in stable condition after 4 days.

Keywords: Fibrous dysplasia (FD); MRI; Right Iliac Bone (RIB)

Introduction

Fibrous dysplasia is a rare disorder of bone which has a non-inheritable genetic origin. Lichtenstein was first who coined the term Fibrous dysplasia (FD) in 1938 [1].

Fibrous dysplasia (FD) is defined as a rare developmental disorder of bone in which osteoblasts cells abnormally differentiate leading to formation of abnormal woven immature bone in place of normal cancellous bone $[1,2]$.

The prevalence of FD has been estimated almost 1/30,000 [3]. Both genders are equally affected [4]. It is usually an incidental imaging finding.

FD is caused by missense gene mutation at chromosome 20q13. FD can involve a single bone called as monostotic FD or involve multiple bones called polyostotic FD. 
It is a slowly progressive disease which can involve any bone in human body but the long bone, skull, and ribs most commonly affected $[4,5]$. FD localized to long bones is easy to diagnose in light of adequate clinical and radiological information and typically through microscopic findings.

This report is a rare case which has not been reported earlier. The case is about the monostotic fibrous dysplasia of right hip bone.

\section{Results}

\section{Case report}

A 24 years old female visited hospital with a complaint of right hip pain and backache, for last 07 months. Pain was dull in nature, increased both in frequency and intensity with the course of time, radiating to right leg, aggravated by movements. Patient had a previous history of 03 months aggressive gym exercises till February2019 when she developed this pain. There was a history of Poly Cystic Ovarian Syndrome. There was no history of other systemic illness.

On examination

Pain in right iliac bone
Tenderness in right posterior iliac bone area Peripheral neurovascular status was normal.

On X-Ray

On X-ray of Pelvis (AP-view) there was bubbly appearance of right iliac bone with thickening of the trabeculi in proximal end of both femora. Fibrous dysplasia was considered as differential.

\section{MRI finding}

Right hip and pelvic bone without contrast shows the following findings:

Abnormal bone marrow signals were noted in right iliac bone.

Loss of cortical margins is seen both anteriorly and posteriorly.

White zone of transition is noted. Inferiorly it extends to the superior and anterior acetabular margins (Fig. 1).

Study shows multiple, variable sized low attenuating (10-15 HU) foci within the right iliac bones. The largest lesion measured $16^{*} 14 * 24 \mathrm{~mm}$ and is located in roof of right acetabulum. The appearance essentially represents a non-aggressive pathologyfibrous dysplasia (Fig. 2).

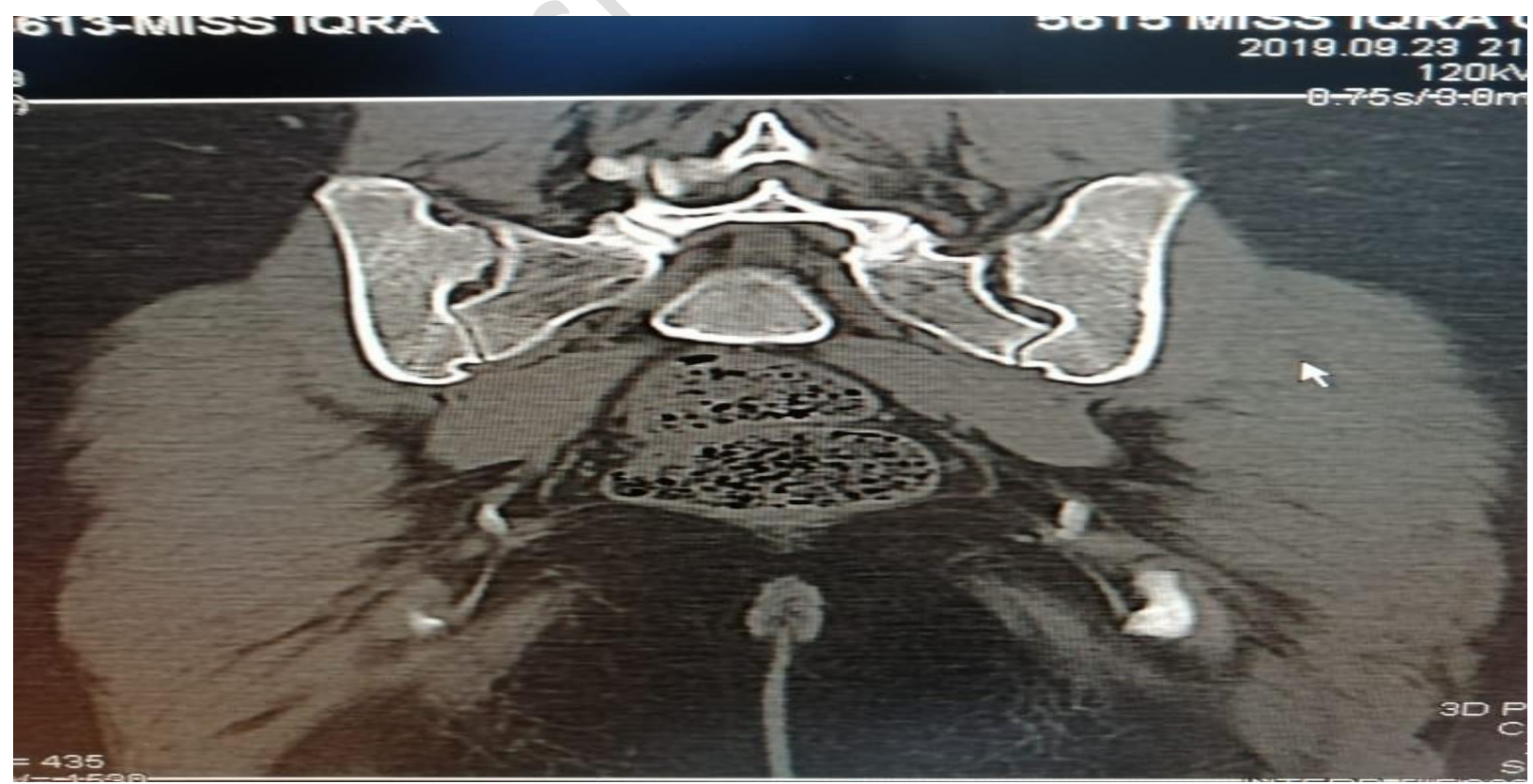

Figure 1. 3D computed tomography scan of pelvis 


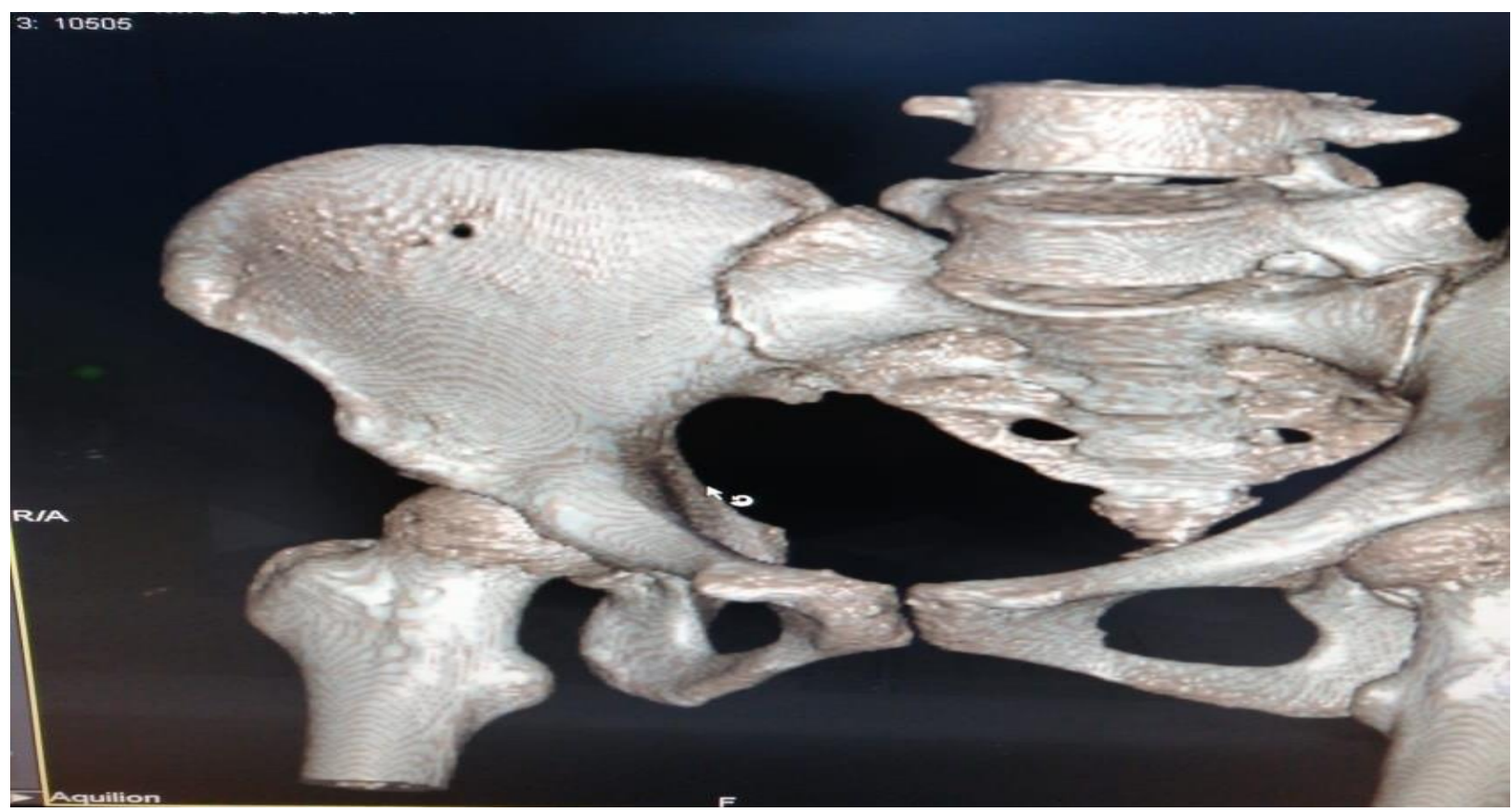

Figure 2. Magnetic resonance image

\section{Histopathology}

Biopsy was taken from right acetabulum and right iliac bone. Histopathology reports disclosed:

The blood and scattered inflammatory cells. There was strong suspicion of fibrous dysplasia.

No neoplastic cells were found.

\section{LAB reports}

$\mathrm{Hb} .=10.6 \mathrm{~g} / \mathrm{dl}$

TLC $=11000$ cells $/ \mathrm{ml}$

DLC $=n=63 \mathrm{l}=18 \mathrm{~m}=1 \mathrm{e}=0 \mathrm{~b}=0$

$\mathrm{ESR}=35 \mathrm{~mm} 0 / 1^{\mathrm{st}} \mathrm{hr}$ and $\mathrm{CRP}=6.29 \mathrm{mg} / \mathrm{dl}$

RA factor $=10.2 \mathrm{IU} / \mathrm{ml}$

Uric Acid=4.0mg/dl

Anti-nuclear antibody $($ ANA $)=0.24$

Anti CCP (cyclic citrullinated peptide $=0.043$

Serum $\mathrm{Ca}=10 \mathrm{mg} / \mathrm{d}$

Serum ALP $=63$ IU/L

Serum phosphorus $=2.8 \mathrm{mg} / \mathrm{dl}$

\section{Management}

Patient's reports were discussed in orthopedic conference and decided for surgical evaluation on priority. Patient was admitted for elective surgery. Informed and written consent was obtained. Excision of the lesion and bone grafting was done. Pharmacological interventions were analgesics, antibiotics, bisphosphonates, oral calcium supplements and proton pump inhibitors. Patient reported $70-80 \%$ reduction in overall symptoms after surgery. Patient was discharged from hospital in stable condition after 4 days with the direction of complete bed rest for 02 weeks, oral medications, regular physiotherapy, and avoidance of bending, sqauatting and lifting. Nursing interventions

Provision of specific care such as management of pain, wound care, infection prevention, high calcium diet, and early mobilization to prevent deep vein thrombosis and physiotherapy.

\section{Discussion}

FD is a relatively uncommon bone disorder with $07 \%$ benign lesions and only $0.8 \%$ is primary lesions. In $70-80 \%$ of cases it is monostotic and 20-30\% of cases are polyostotic. The presenting age ranges from 
10 to 70 years with the majority of cases $(75 \%)$ present before 30 years of age $[4,6-8]$. It is associated with missense gene mutation at chromosome 20q13. Osteoblasts with this mutation had an increase in the proliferation and faulty differentiation leading to fibrotic bone matrix $[4,9]$.

Fibrous dysplasia when polyostotic may be associated with McCune-Albright syndrome and Mazabraud's syndrome [7, 10]. Polyostotic Fibrous dysplasia is more extensive and aggressive as compared to the monostotic lesions. These lesions generally progress till skeletal maturity and then become quiescent [11]. Monostotic lesions never transform into a polyostotic lesion. The disease generally becomes inactive after puberty [12].

Histologically the lesion of FD is usually well differentiated and well circumscribed. It consists of fibrous cellular tissue with spindle cells proliferation and bare mitotic activity. Some nests of woven bones are also present without any significant osteoblastic rimming. Some bony spicules are also present in the curvilinear, "Chinese alphabet" pattern [11]. Malignant transformation causes rapid increase in the size of the lesion but is rarely seen with an incidence of $0.5 \%$ in patients of monostotic FD. In McCune-Albright syndrome the incidence increases to $4 \%$. It can also develop after bone irradiation. Osteosarcoma is the commonest malignant transformation and it is followed by fibrosarcoma, chondrosarcoma and malignant fibrous histiocytoma $[5,13]$.

Low grade osteosarcoma may mimic fibrous dysplasia. It maybe differentiated with the help of imaging and radiological features. Radiographic changes suggesting malignancy are lytic regions, intralesional calcification, periosteal reaction and a cortical disruption $[1,2]$.

\section{Conclusion}

Clinically the malady of stringy dysplasia shows itself within the frame of more or less excruciating bone distortions, development disarranges and in portion broad osteolyses with change zones counting unconstrained break. Harmful changes into high-grade-fibro osteosarcomas are exceptionally rare. Preferred destinations are the long empty bones, which in a few cases are influenced in their aggregate. Hence the rate of dispersion of the injuries run to approximately $36 \%$ influencing the femur, $19 \%$ influence the tibia, the ribs additionally the calvaria are influenced in $10 \%$ and $17 \%$, individually. On the premise of this case report it can be appeared that in all cases of an osteolytic injury it is imperative to carry out a correct preoperative determination. Besides the determination of sinewy dysplasia ought to be included into the differential conclusion in arrange to be able to form with the correct choice on treatment within the conclusion.

\section{Authors' contributions}

Conceived and designed the experiments: $\mathrm{H}$ Aslam \& $\mathrm{N}$ Yousef, Performed the experiments: H Aslam, Contributed reagents/ materials/ analysis tools: S Sehar, Wrote the paper: H Aslam \& N Yousef.

\section{References}

1. Ozdemir-Kutbay N, Sarer-Yurekli B, Kartal-Baykan E, Baydur-Sahin S \& Saygili F (2015). Characteristics and treatment results of 5 patients with fibrous dysplasia and review of the literature. Case Reports in Endocrinol 2015.

2. Riminucci M, Fisher LW, Shenker A, Spiegel AM, Bianco P \& Robey PG (1997). Fibrous dysplasia of bone in the McCune-Albright syndrome: abnormalities in bone formation. The American J of Pathol 151(6): 1587.

3. Kransdorf M, Moser Jr R \& Gilkey F (1990). Fibrous dysplasia. Radiographics 10(3): 519-537.

4. Ayadi-Kaddour A, Ben SS, Marghli A, Mehouachi R, Djilani H, Kilani T \& El FM (2008). Fibrous dysplasia of the rib. 
Ten case reports. Revue De Chirurgie Orthopedique Et Reparatrice De L'appareil Moteur 94(3): 301-307.

5. Thomsen MD \& Rejnmark L (2014). Clinical and radiological observations in a case series of 26 patients with fibrous dysplasia. Calcified Tissue Inter 94(4): 384-395.

6. Henry A (1969). Monostotic fibrous dysplasia. The Journal of bone and joint surgery. British 51(2): 300-306.

7. Singer FR (1997). Fibrous dysplasia of bone: the bone lesion unmasked. The American J of Pathol 151(6): 1511.

8. Snieders MN, Van-Kemenade FJ \& Van-Royen BJ (2009). Monostotic fibrous dysplasia of a lumbar vertebral body with secondary aneurysmal bone cyst formation: a case report. $J$ of $\mathrm{Med}$ Case Rep 3(1): 7227.

9. Mahadevappa A, Patel S, Ravishankar S \& Manjunath GV (2012). Monostotic fibrous dysplasia of the rib: a case report. Case Rep in Orthopedics 2012.

10. Fitzpatrick KA, Taljanovic MS, Speer DP, Graham AR, Jacobson JA, Barnes GR \& Hunter TB (2004). Imaging findings of fibrous dysplasia with histopathologic and intraoperative correlation. American $J$ of Roentgenol 182(6): 1389-1398.

11. Remotti F \& Feldman F (2012). Nonneoplastic lesions that simulate primary tumors of bone. Archives of Pathol \& Lab Med 136(7): 772-788.

12. Case DB, Chapman Jr CN, Freeman JK \& Polga JP (2010). Atypical Presentation of Polyostotic Fibrous Dysplasia with Myxoma (Mazabraud Syndrome). Radiographics 30(3): 827832.

13. Liens D, Delmas PD \& Meunier $P$ (1994). Long-term effects of intravenous pamidronate in fibrous dysplasia of bone. The Lancet 343(8903): 953-954. 